(C) 2020, The Authors. Published by FASS Inc. and Elsevier Inc. on behalf of the American Dairy Science Association ${ }^{\circledR}$.

This is an open access article under the CC BY-NC-ND license (http://creativecommons.org/licenses/by-nc-nd/4.0/).

\title{
Hepatic one-carbon metabolism enzyme activities and intermediate metabolites are altered by prepartum body condition score and plane of nutrition in grazing Holstein dairy cows
}

\author{
M. Vailati-Riboni, ${ }^{1} \odot$ M. Crookenden, ${ }^{2} \odot$ J. K. Kay, ${ }^{2} \odot$ S. Meier, ${ }^{2} \odot$ M. D. Mitchell, ${ }^{3}$ A. Heiser, ${ }^{4} \odot$ J. R. Roche, ${ }^{2,5 *} \odot$ \\ and J. J. Loor $^{1}+$ (D) \\ ${ }^{1}$ Department of Animal Sciences and Division of Nutritional Sciences, University of Illinois, Urbana 61801 \\ ${ }^{2}$ DairyNZ Limited, Private Bag 3221, Hamilton, New Zealand 3240 \\ ${ }^{3}$ Centre for Clinical Research, Royal Brisbane and Women's Hospital Campus, University of Queensland, Herston, Queensland 4029, Australia \\ ${ }^{4}$ AgResearch, Hopkirk Research Institute, Grasslands Research Centre, Palmerston North, New Zealand 4442 \\ ${ }^{5}$ School of Biological Sciences, University of Auckland, Private Bag 92019, Auckland, New Zealand 1142
}

\section{ABSTRACT}

Precalving feeding level and body condition score (BCS) alter postcalving energy balance and oxidant status of dairy cows. We hypothesized that the reported benefits of a controlled restriction precalving depend on precalving BCS. The objective was to identify alterations in activity and intermediates of the hepatic onecarbon metabolism, transsulfuration, and tricarboxylic acid pathways. Twenty-eight pregnant and nonlactating grazing dairy cows of mixed age and breed (Friesian, Friesian $\times$ Jersey) were randomly allocated to 1 of 4 treatment groups in a $2 \times 2$ factorial design: 2 prepartum BCS categories [4.0 (thin, BCS4) and 5.0 (optimal, BCS5); 10-point scale], by managing cows in late lactation to achieve the 2 groups at dry-off, and 2 levels of energy intake during the 3 wk preceding calving (75 or $125 \%$ of estimated requirements), obtained via allowance $\left(\mathrm{m}^{2} / \mathrm{cow}\right)$ of fresh pasture composed of mostly perennial ryegrass and white cover. Average $( \pm$ standard deviation) age was $6 \pm 2,6 \pm 3,5 \pm 1$, and $7 \pm 3 \mathrm{yr}$ for BCS4 fed 75 and 125\%, and BCS5 fed 75 and $125 \%$, respectively. Breed distribution (average \pm standard deviation) for the 4 groups was $79 \pm 21,92$ $\pm 11,87 \pm 31$, and $74 \pm 23 \%$ Friesian, and $17 \pm 20$, $8 \pm 11,13 \pm 31$, and $25 \pm 23 \%$ Jersey. Liver tissue was collected by biopsy at $-7,7$, and 28 d relative to calving. Tissue was used for ${ }^{14} \mathrm{C}$ radio-labeling assays to measure betaine-homocysteine S-methyltransferase,

Received April 13, 2019.

Accepted October 29, 2019.

*Current address: Ministry for Primary Industries, Pastoral House, Lambton Quay, Wellington, New Zealand 6011.

†Corresponding author: jloor@illinois.edu 5-methyltetrahydrofolate-homocysteine methyltransferase (MTR), and cystathionine- $\beta$-synthase (CBS) activity. Liver metabolomics was undertaken using a targeted liquid chromatography with tandem mass spectrometry-based profiling approach. After initial liquid chromatography separation, mass spectra were acquired under both positive and negative ionization, whereas multiple reaction monitoring was used to measure target compound signal response (peak area count). Enzyme activity and metabolite peak area count were normalized with the homogenate protein concentration. Repeated measures analysis of variance via PROC MIXED in SAS (SAS Institute Inc., Cary, $\mathrm{NC}$ ), with BCS, feeding, and time as fixed effects, and cow as random effect was used. All enzyme activities were affected by time, with betaine-homocysteine Smethyltransferase activity peaking at $7 \mathrm{~d}$, whereas CBS and MTR activity decreased postpartum. Overall, thin cows had greater MTR activity, whereas cows fed $125 \%$ requirements had greater CBS activity. An interaction was detected between BCS and feeding for CBS activity, as thin cows fed $125 \%$ of requirements had greater overall activity. Compared with liver from BCS4 cows, BCS5 cows had overall greater betaine, glycine, butyrobetaine/acetylcholine, serine, and taurine concentrations. The same metabolites, plus choline and $\mathrm{N}-\mathrm{N}$ dimethylglycine, were overall greater in liver of cows fed $75 \%$ compared with those fed $125 \%$ of requirements. An interaction of BCS and feeding level was detected for the aforementioned metabolites plus methionine, cystathionine, cysteinesulfinate, and hypotaurine, due to greater overall concentrations in BCS5 cows fed $75 \%$ of requirements compared with other groups. Overall, differences in hepatic enzyme activity and intermediate metabolites suggest that both BCS and feeding level can alter the internal antioxidant system (e.g., glutathione and taurine) throughout the periparturient 
period. Further studies are needed to better understand potential mechanisms involved.

Key words: body condition score, prepartum nutrition, one-carbon metabolism

\section{INTRODUCTION}

The advantage of a pasture-based dairy system is centered around the low cost of pasture compared with more controlled TMR systems, based on conserved forages and concentrates. For their profitability, grazing systems depend on high levels of pasture production, and on the efficiency with which cows are able to harvest it (Kolver, 2003). However, in seasonal systems lower pasture availability in late lactation causes a loss of BCS. Herds in this system may then reach dry-off, and possibly parturition, at a suboptimal level of adiposity (Roche et al., 2007), forcing producers to increase pasture availability per head during the dry period to help animals regain loss reserves.

Despite being introduced in the early 1900s (Boutflour (1928), compared with a controlled limit-feeding, this historical nutritional strategy of increasing energy availability prepartum (e.g., "steaming-up") has been shown in more intensive TMR-based systems to have detrimental effects on animal health, productivity, and reproduction (Grummer, 2008; Grummer et al., 2010). As physiological outcomes induced by overfeeding or levels of BCS prepartum are similar in spectrum and scope (Roche et al., 2015), we postulated that animals of different BCS need to be managed separately prepartum, with feed restriction implemented for optimally conditioned animals, and overfeeding limited only to suboptimally conditioned animals in the 3 wk leading to parturition (Roche et al., 2015; Vailati-Riboni et al., 2016a,b).

In our recent work (Vailati-Riboni et al., 2016b), we identified hepatic transcriptomic changes related to the methionine cycle (e.g., folate biosynthesis, one-carbon pool by folate, and vitamin $\mathrm{B}_{6}$ metabolism) when underconditioned cows were allowed a higher pasture area prepartum. The changes detected in these 3 pathways seemed to indicate a greater flux through the onecarbon metabolism and the methionine cycle, with a potential increase in the availability of methionine and antioxidants. The one-carbon metabolism pathway comprises a network involving interactions among several B vitamins, homocysteine, and methionine. Its function is not limited to regeneration of methionine via remethylation of homocysteine [e.g., betaine homocysteine methyltransferase (BHMT), 5-methyltetrahydrofolate-homocysteine methyltransferase (MTR)], as methionine is further converted to S-adenosyl-methionine (Zhou et al., 2018). This step increases the functions of one-carbon metabolism, as methyl groups in S-adenosyl-methionine can be donated to form a wide-range of vitally important methylated compounds including creatine, epinephrine, and sarcosine, as well as methylated DNA, RNA, and proteins (Ducker and Rabinowitz, 2017).

The one-carbon metabolism further connects to the animal's antioxidant system via the transsulfuration pathway. Homocysteine together with serine are used as substrates by cystathionine $\beta$-synthase (CBS) to generate cystathionine and then cysteine, leading to the synthesis of both glutathione and taurine, powerful cellular antioxidants. The onset of lactation in dairy cows is characterized by well-known physiologic challenges including negative energy balance (NEB), inflammatory environment, and overproduction of reactive oxygen species (ROS), which leads to oxidative stress (Loor et al., 2013a,b). The latter in particular has been identified as an underlying factor of dysfunctional inflammatory responses (Abuelo et al., 2015), underscoring the importance of the transsulfuration pathway in keeping an adequate supply of antioxidants (Coleman et al., 2019; Vailati-Riboni et al., 2019).

As both BCS (Roche et al., 2015) and prepartum feeding level (Loor et al., 2006; Graugnard et al., 2012; Graugnard et al., 2013) have been connected to alterations with the cow's inflammatory and antioxidant status, we hypothesized that BCS, prepartum feeding management, and their interaction alters components of the one-carbon metabolism and transsulfuration pathway. Thus, to better understand adaptations in activity and flux through the one-carbon metabolism, methionine cycle, and transsulfuration pathway in response to prepartum feed allowance and its interaction with BCS, we focused on hepatic tissue, which together with kidney, are the only organs with the complete repertoire of enzymes in one-carbon metabolism and transsulfuration (Ducker and Rabinowitz, 2017). Specific objectives were to evaluate activity of 3 key enzymes of one-carbon metabolism within the context of dryoff BCS and prepartum plane of nutrition: (1) BHMT, which regulates the use of choline in the re-methylation of homocysteine, thus, regenerating methionine; (2) MTR, responsible for the methylation of homocysteine to regenerate methionine via the folate pathway; and (3) CBS, which channels homocysteine out of the cycle to generate glutathionine or taurine as important antioxidants. Furthermore, we also measured abundance of genes and concentration of metabolites involved in these pathways and energy metabolism. 


\section{MATERIALS AND METHODS}

\section{Animal Management}

The Ruakura Animal Ethics Committee (Hamilton, New Zealand) approved all animal manipulations in accordance with the New Zealand Animal Welfare Act (1999; http://www.legislation.govt.nz/act/public/ 1999/0142/latest/DLM49664.html?search=ts_act \%40bill\%40regulation\%40deemedreg_animal+welfare _resel_25_a\&p=1). The experiment was undertaken at Scott Farm, Hamilton, New Zealand $\left(37^{\circ} 46^{\prime} \mathrm{S} 175^{\circ} 18^{\prime} \mathrm{E}\right)$, between January and October 2013. Complete details of the experimental design are published elsewhere (Roche et al., 2015). Briefly, a group of 150 mid-lactation grazing dairy cows of mixed age and breed were enrolled in the experiment on January 21, 2013. Animals, at time of enrollment (mid-lactation), were allocated randomly to 1 of 6 treatment groups ( 25 cows per group) in a $2 \times$ 3 factorial arrangement: 2 pre-calving BCS categories (4.0 and 5.0, BCS4 and BCS5; based on a 10-point scale, where 1 is emaciated and 10 obese; Roche et al., 2004) and 3 levels of energy intake during the $3 \mathrm{wk}$ preceding calving, based on expected calving date $(75,100$, and $125 \%$ of estimated requirements). Cows were managed during late lactation to reach the assigned level of BCS at dry-off. After 3 wk before expected calving date, the different levels of energy intake were obtained by daily manipulation of pasture allowance, adjusting area allocation $\left(\mathrm{m}^{2} / \mathrm{cow}\right)$ in each group. Pasture composition is reported elsewhere (Roche et al., 2015). Cows were randomly assigned to the 6 groups, balanced for age, breed (Holstein and Holstein $\times$ Jersey), BCS at the time of enrollment, and expected calving date. For the current study, only 4 groups, with a subset of 28 animals ( 7 cows per group), were considered. These were cows with prepartum BCS4 fed to meet 75 (B4F75) or 125 (B4F125) \% of requirements, and cows with prepartum BCS5 fed to meet 75 (B5F75) or 125 (B5F125) \% of requirements. Average age and days in gestation \pm standard deviation at enrolment was $6.20 \pm 2.18 \mathrm{yr}$ and $259 \pm 2 \mathrm{~d}$, respectively. Mean age was $5.54,6.48,4.75$, and $6.80 \mathrm{yr}$ old, and the average breed composition (\% Holstein/Jersey) was 79.5/17.0, 91.7/8.3, 86.7/13.3, and 74.0/25.0 for B4F75, B4F125, B5F75, and B5F125, respectively.

To align the focus of the present work with previously published work (Vailati-Riboni et al., 2016a,b), the intermediate groups in both BCS classes (B4F100 and B5F100) were omitted from the present analysis. This was done to test the interaction of BCS and prepartal nutritional management, focusing on the historically accepted "steaming-up" practice against the more re- cent research-based strategy of feed restricting animals in the weeks leading to parturition (Roche et al., 2015).

\section{Sample Analysis}

Blood was sampled before the procedure on the same days as liver biopsies by coccygeal venipuncture using evacuated tubes containing a lithium heparin anticoagulant. Samples were processed for plasma collection and determination of biomarkers of metabolism (free

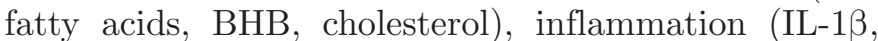
IL-6, haptoglobin), and oxidative stress [total antioxidant capacity (TAC) and ROS]. Assay procedures are reported elsewhere (Roche et al., 2015).

Liver tissue was collected, as previously described (Vailati Riboni et al., 2015), via percutaneous biopsy under local anesthesia at $-7,7$, and $28 \mathrm{~d}$ relative to parturition. Tissue samples were immediately snap frozen in liquid nitrogen and stored at $-80^{\circ} \mathrm{C}$ until further analysis.

Enzyme activity assays were performed as previously described (Zhou et al., 2017). Enzyme assay details are reported in Supplemental File S1 (https://doi.org/10 .3168/jds.2019-16798). Results were normalized against the liver homogenate protein concentration.

For metabolomics analysis, about $50 \mathrm{mg}$ of frozen tissue was extracted by the 2-step protocol described by Wu et al. (2008), which included methanol/chloroform/ water extraction. Briefly, liver was homogenized in 4 and $0.85 \mathrm{~mL}$ of methanol and water per $\mathrm{g}$ of tissue, respectively. Afterward, the homogenate was removed and combined with 4 and $2 \mathrm{~mL}$ of chloroform and water per $\mathrm{g}$ of tissue. Samples were then left to partition on ice for $10 \mathrm{~min}$, and centrifuged to separate the polar and nonpolar layer. Targeted metabolomics [liquid chromatography (LC)/MS/MS] was performed to quantify metabolites related to the one carbon metabolism, the transsulfuration pathway, and tricarboxylic acid (TCA) cycle. The full list of analyzed metabolites can be found in Supplemental Table S1 (https://doi.org/10 .3168/jds.2019-16798). Samples were analyzed with the 5500 QTRAP LC/MS/MS system (Sciex, Framingham, MA). To reduce matrix effects, samples were diluted 5 -fold before analysis. The 1200 series HPLC system (Agilent Technologies, Santa Clara, CA) includes a degasser, an autosampler, and a binary pump. The LC separation was performed on a Phenomenex C18 (2) column $(4.6 \times 150 \mathrm{~mm}, 5 \mu \mathrm{m}$; Torrance, CA $)$ with mobile phase A (10 $\mathrm{m} M$ ammonia formate) and mobile phase B (methanol). The flow rate was $0.4 \mathrm{~mL} / \mathrm{min}$. The linear gradient was as follows: $0-1 \mathrm{~min}, 95 \% \mathrm{~A} ; 8$ min, $50 \%$ A; 15-18 min, 0\% A; 18.1-26 min, 95\% A. The autosampler was set at $10^{\circ} \mathrm{C}$. The injection volume 
was $10 \mu \mathrm{L}$. Mass spectra were acquired under both positive (ion spray voltage was $+5,500 \mathrm{~V}$ ) and negative (ion spray voltage was $-4,500 \mathrm{~V}$ ) electrospray ionization. The source temperature was $500^{\circ} \mathrm{C}$. The curtain gas, ion source gas 1 , and ion source gas 2 were 35 , 65 , and 55 psi, respectively. Multiple reaction monitoring was used for quantitation (Supplemental Table S1; https://doi.org/10.3168/jds.2019-16798). To optimize MS conditions (such as multiple reaction monitoring transitions and related collision energies) for each target metabolite, purified standards acquired from Sigma Aldrich (St. Louis, MO) were used before analysis of samples. Software Analyst 1.6.2 (AB Sciex Pte. Ltd., Singapore) was used for data acquisition and analysis. Before statistical analysis, the peak area count (PAC) was normalized by the protein concentration of the samples.

Total RNA was isolated from $100 \mathrm{mg}$ of tissue using the miRNeasy kit (Qiagen, Hilden, Germany) following the manufacturer's protocols. Samples were treated on-column with DNaseI (Qiagen); quantification was accessed using the NanoDrop ND-1000 (NanoDrop Technologies, Wilmington, DE), and RNA quality was measured using an Agilent 2100 Bioanalyzer (Agilent). The qPCR was performed as described previously (Vailati Riboni et al., 2016). Before statistical analysis, normalized (against internal control genes) gene relative abundance was $\log _{2}$ transformed to ensure a normal distribution.

\section{Statistical Analysis}

Enzyme activity (U.mg of protein ${ }^{-1}$, or $\mathrm{nmol}$ of product $\cdot h^{-1} \cdot \mathrm{mg}$ of protein $\left.{ }^{-1}\right)$, mRNA abundance $\left(\log _{2}\right.$ relative abundance), normalized metabolite PAC $\left(\mathrm{PAC} \cdot \mathrm{mg}\right.$ of protein $^{-1}$ ), and blood biomarkers were subjected to repeated measures ANOVA in SAS version 9.4 (SAS Institute Inc., Cary, NC) using PROC MIXED. Body condition score (B, 4 or 5$)$, feeding (F, 75 or $125 \%)$, time $(\mathbf{T},-1,+1,+4$ wk from parturition), and their interactions $(\mathrm{B} \times \mathrm{F}, \mathrm{B} \times \mathrm{T}, \mathrm{F} \times \mathrm{T}, \mathrm{B} \times \mathrm{F}$ $\times \mathrm{T})$ were used as fixed effects. Cow nested in group $(\mathrm{B} \times \mathrm{F})$ was the random effect. The Kenward-Roger statement was used to compute the degrees of freedom, and spatial power was used as covariance structure for the repeated measurement. Normality of the residuals was checked via PROC UNIVARIATE. Data for metabolites fumarate, $\mathrm{NAD}^{+}, \mathrm{NADH}, \mathrm{NAD}^{+}: \mathrm{NADH}$, adenosine, and cysteinesulfinate and blood haptoglobin concentration were $\log _{2}$ transformed to obtain normality. All other data were normally distributed. Metabolite data reported in tables and graphs were properly back-transformed to aid in their interpretation. The mRNA abundance data were back-transformed only in tables and kept as $\log _{2}$ relative mRNA abundance for figures. Statistical significance was determined at $P \leq$ 0.05 , whereas tendencies were considered at $P \leq 0.10$.

\section{RESULTS}

\section{Blood Biomarkers}

The BCS affected all metabolism biomarkers, with BCS5 cows displaying greater overall levels of NEFA, $\mathrm{BHB}$, and cholesterol. Compared with BCS4, greater $(P<0.001)$ antioxidant capacity and lower levels $(P=$ 0.04 ) or ROS were also observed for BCS5 cows (Table 1). Regarding cholesterol, an interaction with time ( $P$ $=0.03$ ) indicated that the effect of BCS was due to greater levels for BCS5 compared with BCS4 only at 4 wk postpartum, whereas the same interaction indicated that antioxidant levels were greater in BCS5 cows prepartum and 1 wk postpartum, not late postpartum $(P$ $<0.001)$. Interactions of BCS and time were detected for IL-1 $\beta(P=0.05)$ and haptoglobin $(P=0.01)$. Concentration of IL-1 $\beta$ was greater at 4 wk postpartum in BCS4 compared with BCS5 cows, whereas haptoglobin levels were greater prepartum in BCS4 compared with BCS5 cows.

Feeding level only affected cholesterol, haptoglobin, and antioxidant capacity (Table 1), as feeding $125 \%$ of requirements led to lower levels of the first $(P=$ $0.001)$ and greater levels of the latter $2(P=0.03$ and $P<0.001)$. An interaction between feeding level and time $(P<0.001)$ indicated that feeding at $125 \%$ of requirements compared with $75 \%$ sustained the greatest level of antioxidant capacity throughout all time points measured in the current experiment. Only the interaction of BCS and feeding level $(P<0.001)$ affected antioxidant levels. Optimally conditioned cows fed at $125 \%$ of requirements (B5F125) had overall greater levels of antioxidant capacity compared with other groups. A 3-way interaction of BCS, feeding, and time (Table $1)$ was observed for antioxidant capacity $(P<0.001)$. Independent of feeding, compared with BCS4, BCS5 cows had greater TAC prepartum. Instead, postpartum B5F125 cows had higher TAC levels compared with other groups at $1 \mathrm{wk}$ from parturition, whereas at $4 \mathrm{wk}$ B5F75 cows had the lowest TAC compared with other groups.

\section{One-Carbon Metabolism}

Body condition score, feeding, and their interaction had no statistical effect on BHMT activity $(P>0.05)$, which was, however, affected by time, with greater activity ( 1 vs. -1 wk, $P=0.02 ; 4$ vs. $-1, P=0.07$ ) postpartum compared with prepartum (Table 2, Fig- 
ure 1). The significant interaction $(P=0.05)$ between feeding level and time indicated that cows fed to $75 \%$ of requirements had stable BHMT enzyme activity throughout the transition period, whereas cows overfed to $125 \%$ of requirements experienced an increase in activity postpartum. Furthermore, compared with overfed, restricted cows tended $(P=0.07)$ to have greater activity prepartum. The MTR activity was influence by time $(P<0.001)$, but with an opposite trend. Activity was highest prepartum and then decreased over time ( -1 vs. 1 wk, $P=0.06 ;-1$ vs. 4 wk, $P<0.001)$. Feeding strategy did not statistically alter its activity, but thin animals (BCS4) had a lower $(P=0.001)$ activity of MTR compared with optimally conditioned cows (BCS5).

Abundance of MAT2A and MTR was stable over time $(P>0.05$; Table 3$)$, whereas BHMT1 followed the enzyme activity trend, with greater $(P<0.05)$ abundance postpartum compared with prepartum (Table 3, Figure 2). Abundance of MAT2A was greater in optimally conditioned cows $(P=0.004)$, whereas no statistical effects of BCS $(P>0.05)$ were identified for BHMT1 and MTR. Overfeeding animals prepartum induced an overall lower abundance of both MAT2A and MTR $(P<0.05)$, but not BHMT1 $(P>0.05)$. No statistical interaction of BCS and feeding $(P>0.05)$ was recorded for these genes related to the one-carbon metabolism. Three-way interactions were detected for all 3 genes $(P<0.05)$.

A time effect existed for all metabolites $(P<0.05$; Table 4). Except for adenosine and S-5'-adenosylhomocysteine, whose PAC decreased $(P<0.05)$ postpartum, all metabolites in this pathway increased $(P$ $<0.05)$ in PAC postpartum compared with prepartum (Table 4, Figure 3). Compared with thin cows, optimally conditioned cows had greater $(P<0.05)$ PAC of betaine, carnitine, choline, glycine, and butyrobetaine/acetylcholine in liver tissue. Compared with feed restriction, overfeeding decreased $(P<0.05)$ the concentration of these metabolites, overall, including that of $N, N$-dimethylglycine (N,N-DG). Interactions of BCS and feeding $(P<0.05)$ were detected for betaine, choline, glycine, methionine, N,N-DG, and butyrobetaine/acetylcholine. Compared with all other groups, betaine, choline, carnitine, glycine, and N,N-DG PAC were greatest $(P<0.05)$ in feed-restricted, optimally conditioned cows. The peak PAC of methionine was, instead, detected for B5F75 and B4F125 cows, whereas butyrobetaine/acetylcholine was greatest in B5F75 cows, followed by B5F125, and then both BCS4 groups.

Interactions of BCS and feeding with time were detected for carnitine, glycine, and butyrobetaine/acetylcholine $(P<0.05$; Table 4, Figure 4). Overall, BCS5 compared with BCS4 or feed-restricted compared with 


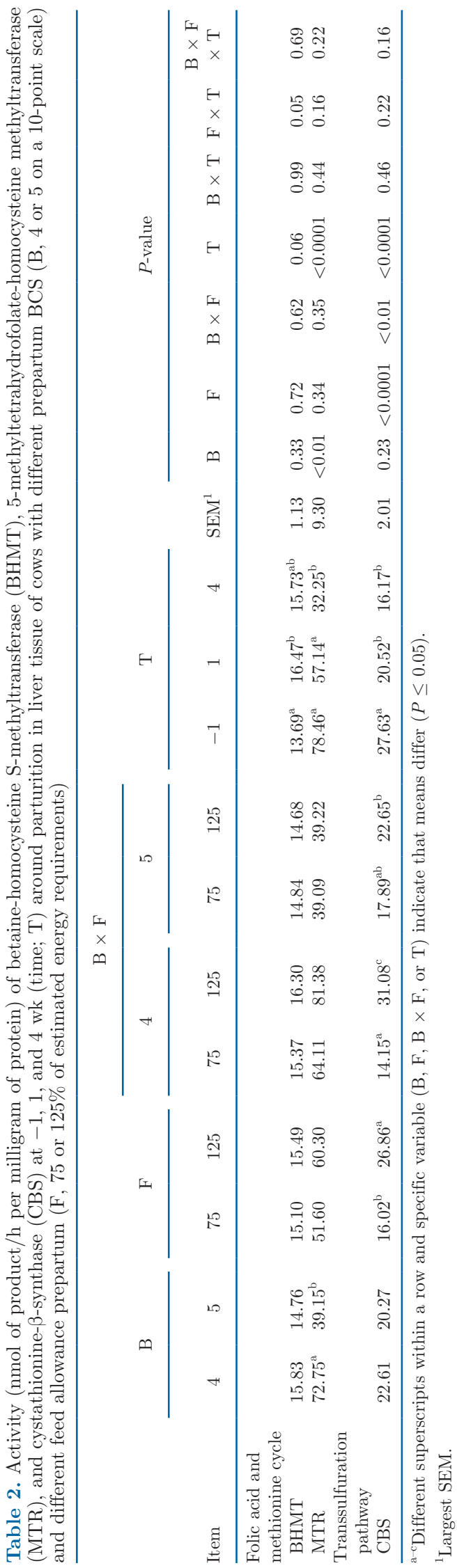

overfed cows had greater postpartal carnitine PAC at 4 wk. Feed-restricted cows also had greater $(P<0.05)$ levels of carnitine prepartum ( $-1 \mathrm{wk})$. The PAC of glycine in BCS4 and BCS5 cows were similar at -1 and 1 wk relative to calving, but differed at 4 wk postpartum, with greater values in BCS5 cows. Similarly, cows feedrestricted and overfed had similar PAC of glycine at -1 and 1 wk relative to parturition, but feed-restricted animals had higher glycine 4 wk from calving. Regarding butyrobetaine/acetylcholine, compared with BCS4, $\mathrm{PAC}$ was greater in BCS5 cows both prepartum and at

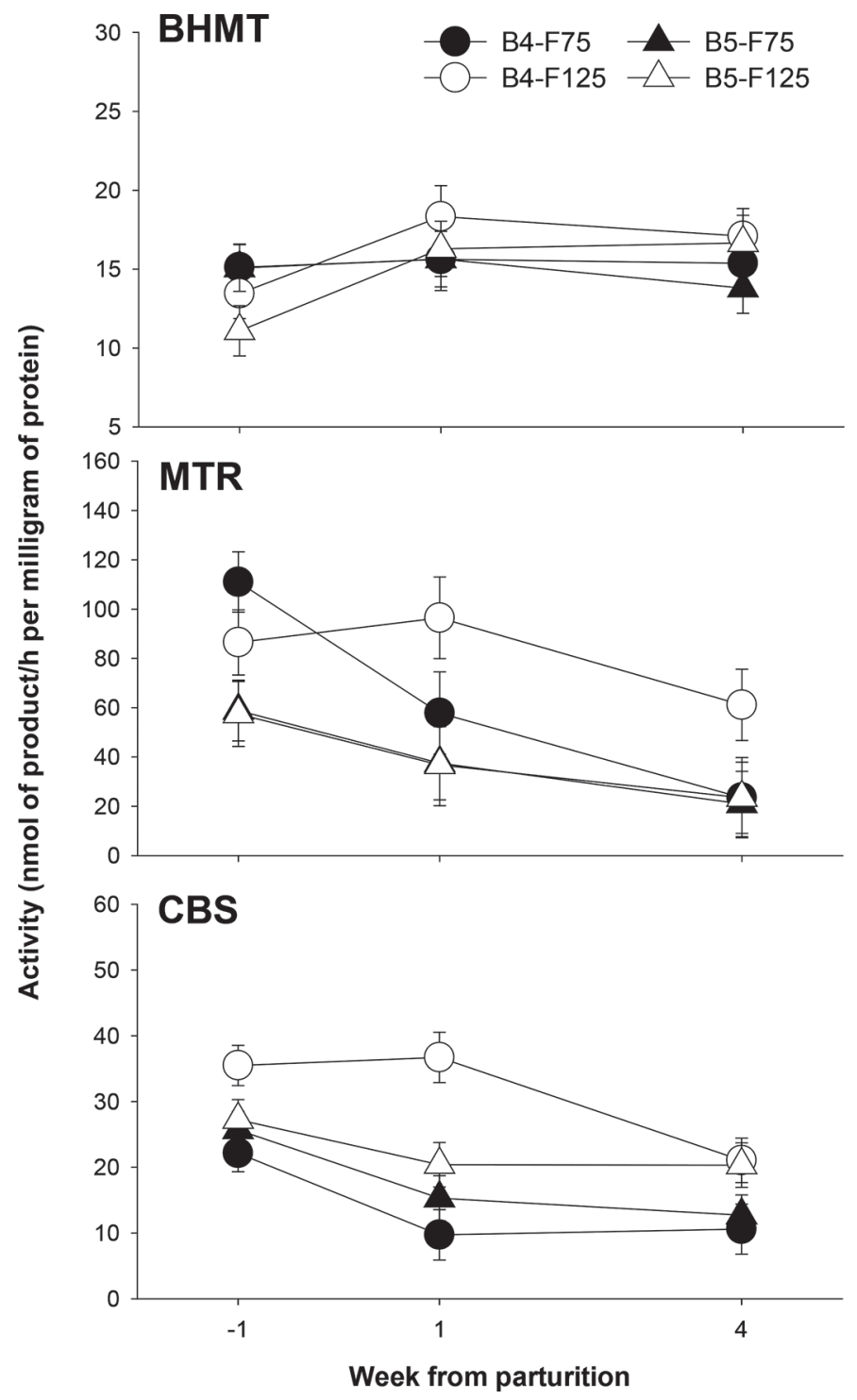

Figure 1. Activity (nmol of product/h per milligram of protein) of betaine-homocysteine S-methyltransferase (BHMT), 5-methyltetrahydrofolate-homocysteine methyltransferase (MTR), and cystathionine$\beta$-synthase (CBS) at $-1,1$, and $4 \mathrm{wk}$ around parturition in liver tissue of cows with different prepartum BCS (B, 4 or 5 on a 10-point scale) and different feed allowance prepartum (F, 75 or $125 \%$ of estimated energy requirements).Values are means, with $\mathrm{SE}$ represented by vertical bars. 


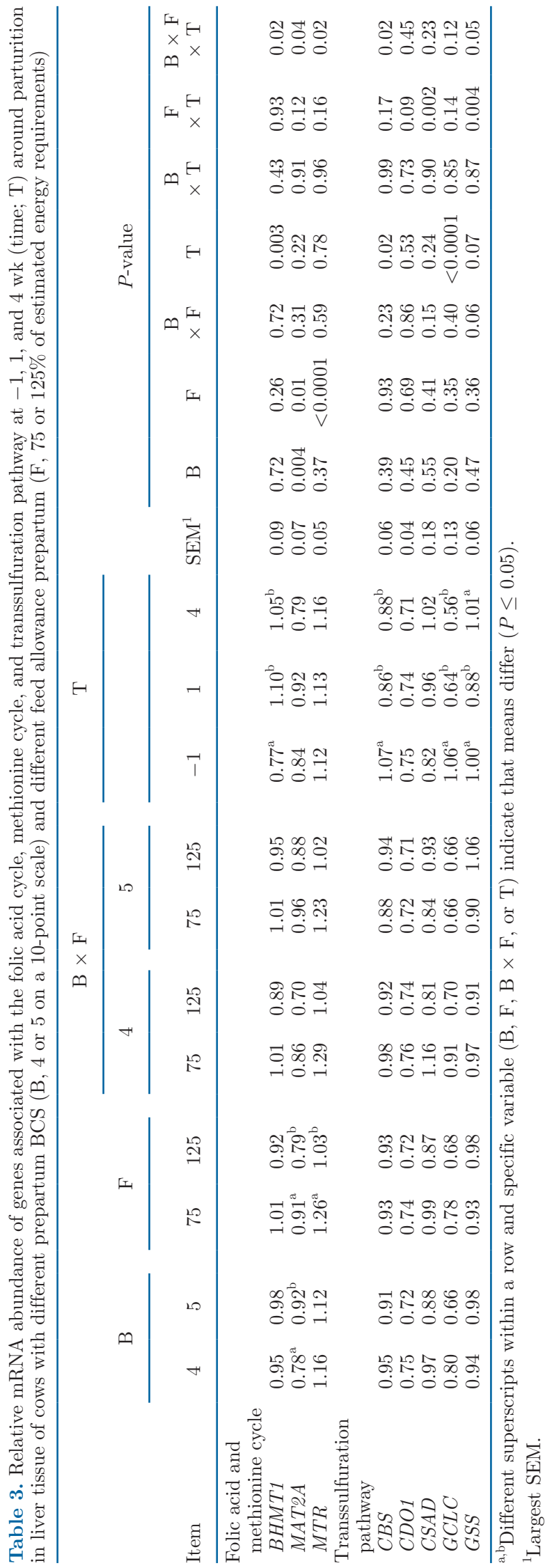

$4 \mathrm{wk}$ postpartum. Similar PAC were detected at $1 \mathrm{wk}$ postpartum between the 2 BCS groups. Feeding level had no statistical effect at -1 and 1 wk from parturition, but affected butyrobetaine/acetylcholine PAC at 4 wk from calving, with restricted cows having greater PAC compared with overfed cows. A 3-way interaction $(P<0.05)$ was identified for butyrobetaine/acetylcholine, carnitine, glycine, and N,N-DG.

\section{Transsulfuration Pathway}

Similar to MTR, CBS activity was lower postpartum $(P<0.05)$ compared with prepartum levels (Table 2 , Figure 1$)$. The BCS did not statistically affect its activity overall $(P=0.23)$, but compared with feed-restricted cows, overfed cows had greater overall CBS activity $(P$ $<0.001$ ). The significant interaction between BCS and feeding $(P=0.004)$ indicated that overfeeding led to greater CBS activity, mostly in thin cows (BCS4) and not in optimally conditioned cows (BCS5).

Compared with prepartum levels, abundance of $C S B$, $G C L C$, and $G S S$ was lower $(P<0.05)$ early postpartum (1 wk; Table 3, Figure 2). Abundance for these 3 genes remained lower later postpartum ( $4 \mathrm{wk})$, but $G S S$ returned to its prepartum level of abundance. No overall statistical effect of BCS, feeding, or their interaction was evident for genes involved in the transsulfuration pathway. Interaction of feeding and time was significant for $C S A D$ and $G S S$ abundance $(P<0.05)$. Compared with overfed cows, CSAD abundance was greater $(P=$ $0.04)$ prepartum in feed-restricted cows. Early postpartum its abundance was similar, but late postpartum feed-restricted had lower $(P=0.01) C S A D$ abundance compared with overfed cows. An opposite trend was detected for GSS abundance, with feed-restricted cows having greater abundance prepartum, followed by lower abundance late postpartum when compared with overfed cows. A 3 -way interaction $(P<0.05)$ was identified for $C B S$ and $G S S$ expression.

Time affected $(P<0.05)$ PAC of cystathionine, hypotaurine, and serine, with higher levels 4 wk postpartum compared with earlier times (Table 4, Figure 4). Overall effects of BCS and feeding were detected only for serine, whose PAC was greater in BCS5 $(P=0.02)$ or feed-restricted $(P=0.001)$ cows. The interaction of BCS and feeding was significant for all metabolites measured $(P<0.05)$. Overall, compared with other groups, feed-restricted optimally conditioned cows had the greatest $(P<0.05)$ PAC of cystathionine and serine. PAC of cysteine sulfonate was greatest $(P$ $<0.05)$ in overfed thin and feed-restricted optimally conditioned cows, whereas hypotaurine was greatest $(P$ $<0.05$ ) for B5F75 compared with B4F75 and B5F125 cows. An interaction of BCS and time was detected for 


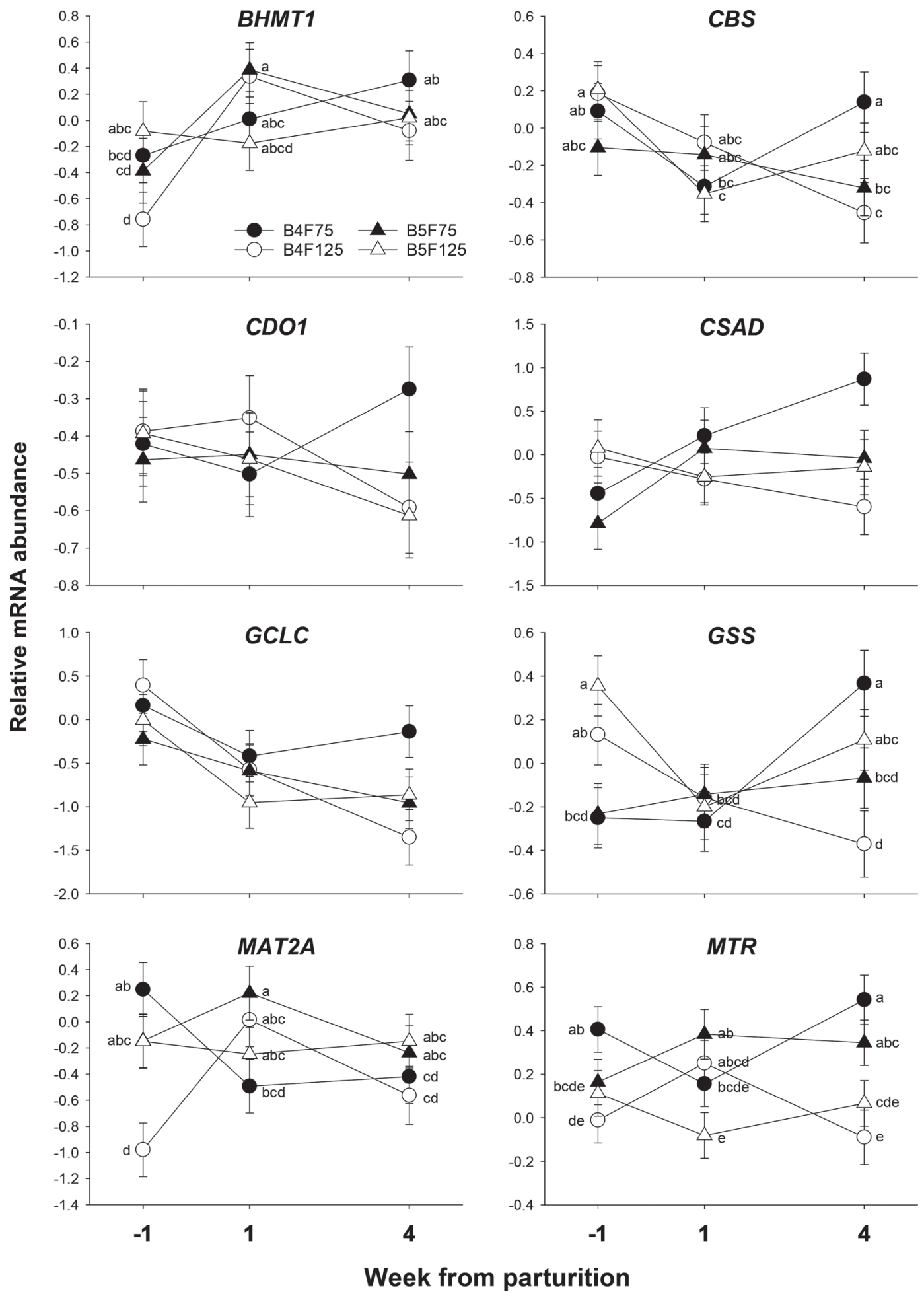

Figure 2. Relative mRNA abundance of genes in the folic acid cycle, methionine cycle, and transsulfuration pathway at $-1,1$, and 4 wk around parturition in liver tissue of cows with different prepartum BCS (B, 4 or 5 on a 10-point scale) and different feed allowance prepartum (F, 75 or $125 \%$ of estimated energy requirements). Different letters (a-e) indicate that means at a given time differ (interaction $P<0.05$ ). Vertical bars denote SEM. 
Vailati-Riboni et al.: GRAZING COWS AND ONE-CARBON METABOLISM

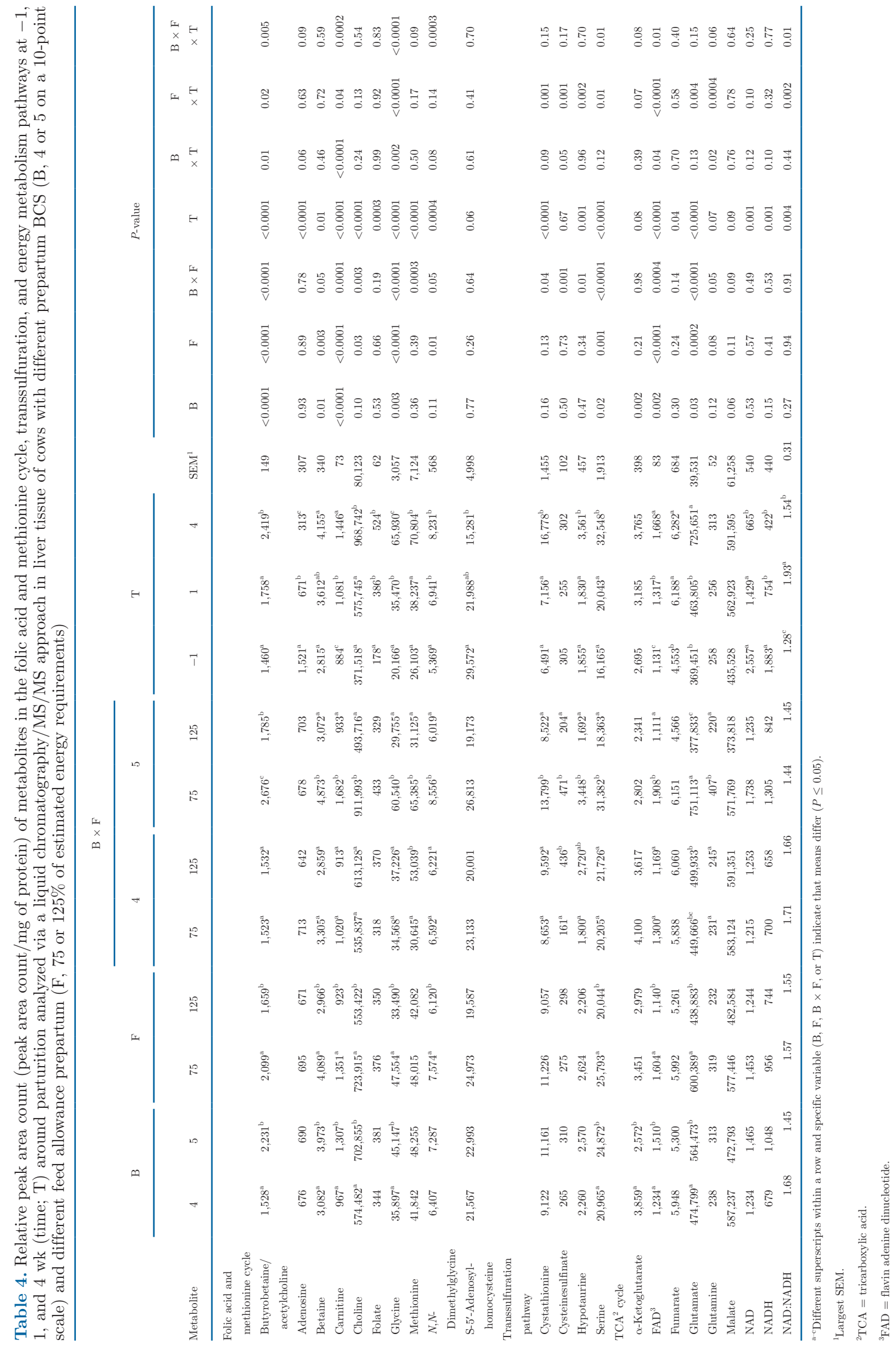



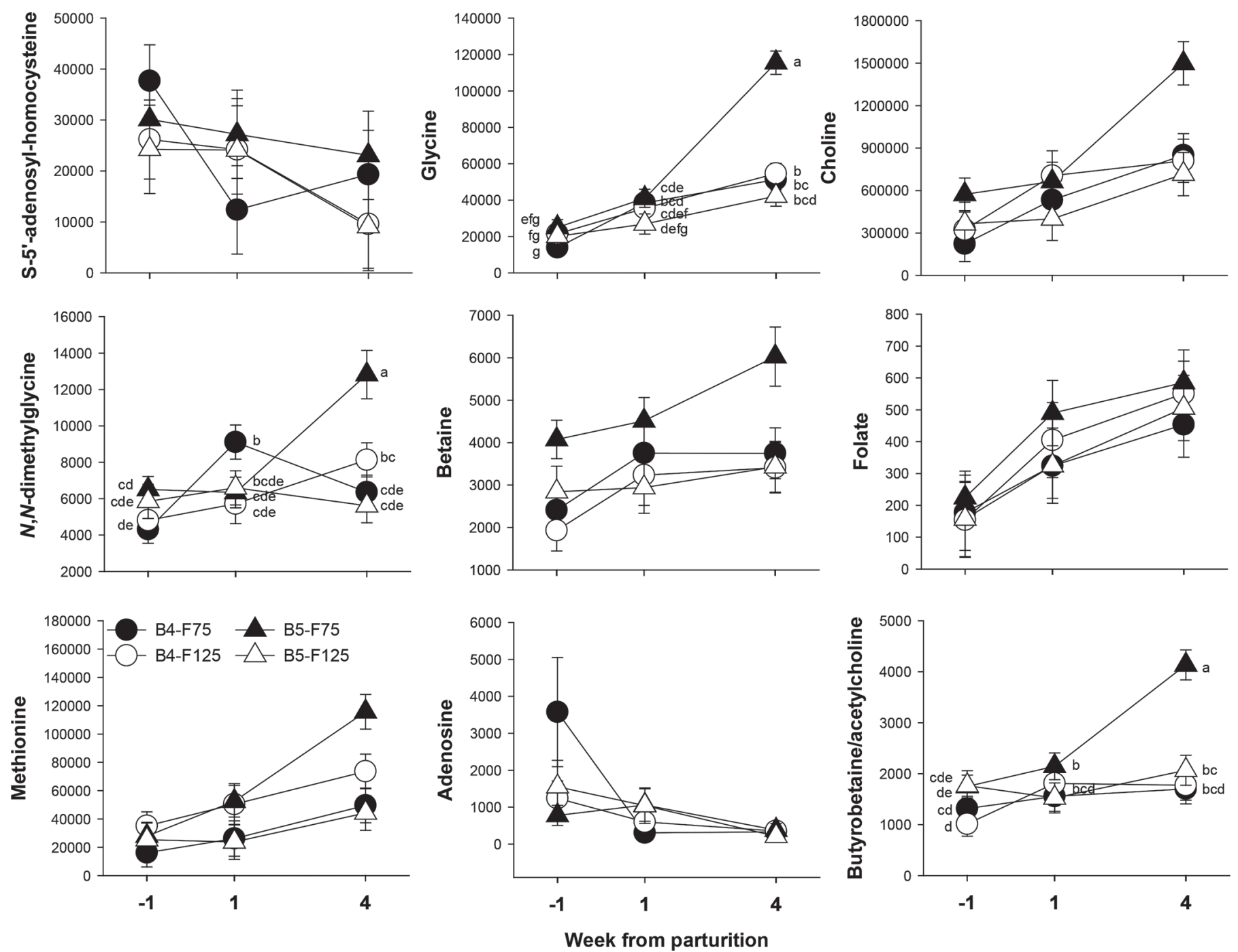

Figure 3. Relative peak area count (PAC/mg of protein) of metabolites in the folic acid and methionine cycle at $-1,1$, and 4 wk around parturition analyzed via a liquid chromatography (LC)/MS/MS approach in liver tissue of cows with different prepartum BCS (B, 4 or 5 on a 10-point scale) and different feed allowance prepartum (F, 75 or 125\% of estimated energy requirements). Means with different letters (a-g) at a given time differ (interaction $P \leq 0.05$ ). Vertical bars denote SEM.

cystathionine $(P=0.05)$, but no difference between BCS groups was detected at any time point. Only a tendency $(P=0.07)$ for greater PAC of cystathionine in BCS5 compared with BCS4 cows at 4 wk postpartum was detected. The interaction of feeding and time was significant for all metabolites measured in the transsulfuration pathway $(P<0.05)$. For all metabolites, no statistical differences were observed between feeding levels at 1 wk postpartum $(P>0.05)$. In contrast, prepartum overfeeding compared with feed restriction tended $(P<0.10)$ to increase PAC of cystathionine, cysteinesulfinate, and hypotaurine, but not serine $(P$ $>0.10)$. It is noteworthy that late postpartum (4 wk) overfeeding compared with feed restriction led to lower
$(P<0.05)$ PAC of all metabolites. A 3-way interaction $(P<0.05)$ was detected for serine.

\section{Energy Metabolism}

Differences due to time were detected for the PAC of flavin adenine dinucleotide (FAD), fumarate, glutamate, $\mathrm{NAD}^{+}$, and $\mathrm{NADH}$, and $\mathrm{NAD}^{+}: \mathrm{NADH}$ ratio $(P$ $<0.05$; Table 4, Figure 5). The PAC of FAD increased linearly over the transition period, whereas fumarate PAC increased to a stable level postpartum. Compared with prepartal PAC, glutamate tended $(P=0.09)$ to be higher around parturition, and increased later in the transition period. In contrast, PAC of $\mathrm{NAD}^{+}$and 
NADH decreased $(P=0.001)$ during the transition period, with the first being stable around calving and declining at 4 wk postpartum, and the latter decreasing after calving to stable levels throughout the postpartal period. In contrast, their ratio increased postpartum, with peak levels right after parturition. Overall, optimally conditioned cows had a greater PAC $(P<0.05)$ of FAD, and glutamate, and lower $(P=0.002)$ PAC of $\alpha$-ketoglutarate compared with thin cows. Feed restriction caused an increase $(P<0.05)$ in PAC of FAD, and glutamate. A BCS and feeding interaction was detected $(P<0.05)$ for FAD, glutamate, and glutamine, as feedrestricted, optimally conditioned cows had greater PAC of these metabolites compared with other cows.

Interactions between BCS and time were detected for FAD and glutamine $(P<0.05)$, with BCS5 cows having greater postpartal PAC of these metabolites at 1 and 4 wk compared with BCS4 cows, and also at $1 \mathrm{wk}$ prepartum (Table 4, Figure 5). The FAD, glutamine, glutamine, and $\mathrm{NAD}^{+}: \mathrm{NADH}$ ratio also had a signifi-
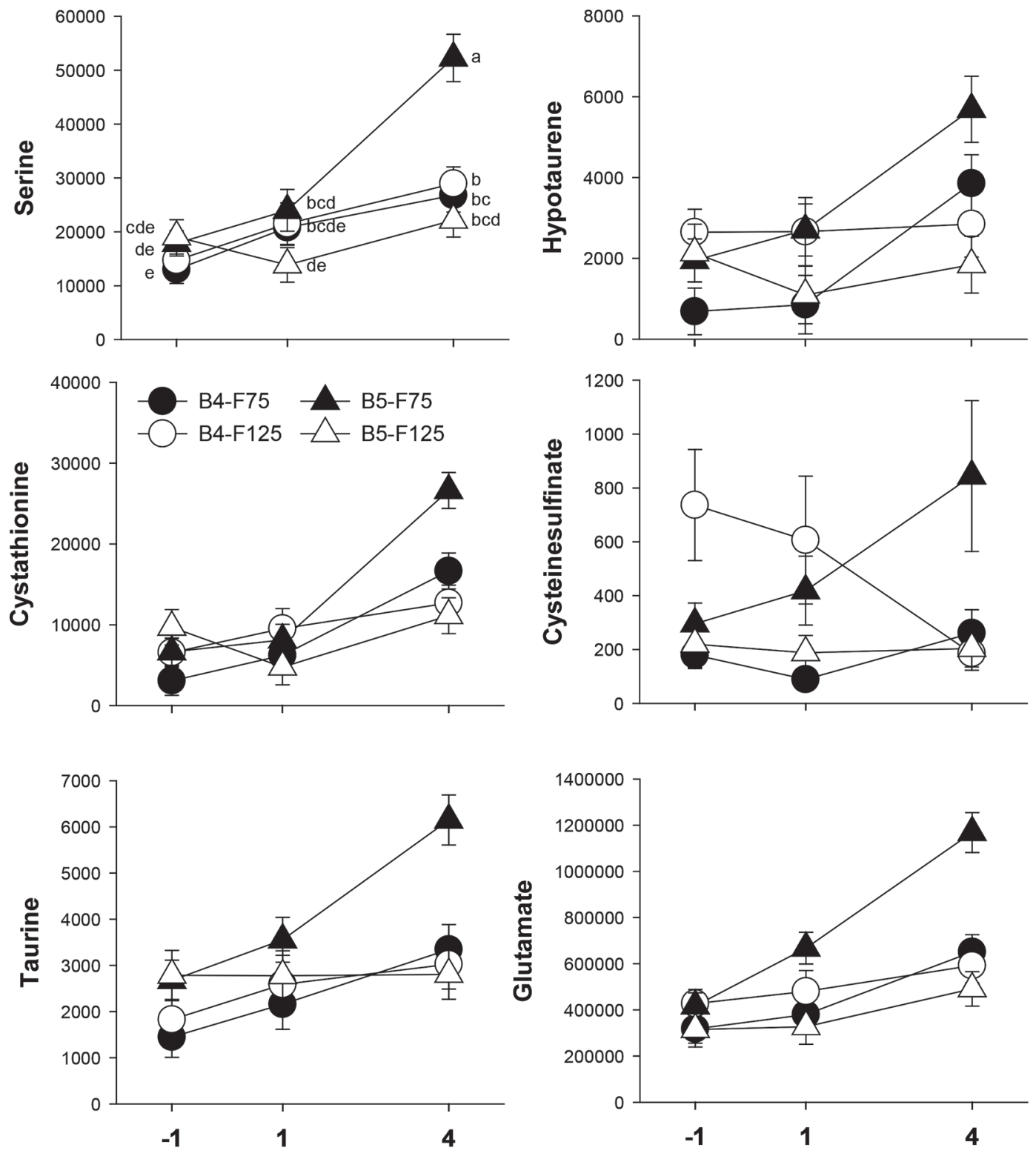

Week from parturition

Figure 4. Relative peak area count (PAC/mg of protein) of metabolites in the hepatic transsulfuration pathway at $-1,1$, and 4 wk around parturition analyzed via a liquid chromatography (LC)/MS/MS approach in liver tissue of cows with different prepartum BCS (B, 4 or 5 on a 10-point scale) and different feed allowance prepartum (F, 75 or $125 \%$ of estimated energy requirements). Means with different letters (a-e) at a given time differ (interaction $P \leq 0.05$ ). Vertical bars denote SEM. 
cant interaction between feeding and time $(P<0.05)$. Compared with overfed cows, feed-restricted cows had greater $(P<0.05)$ PAC of glutamine and FAD postpartum $(1$ and 4 wk), and greater $(P<0.05)$ PAC of glutamate late postpartum $(4 \mathrm{wk})$. The $\mathrm{NAD}^{+}: \mathrm{NADH}$ ratio was greater prepartum in feed-restricted animals, but greater at 1 wk postpartum in overfed cows. A similar ratio between feeding groups was evident at the end of the transition period. A 3-way interaction was detected for FAD and $\mathrm{NAD}^{+}: \mathrm{NADH}$ ratio $(P<0.05)$.

\section{DISCUSSION}

\section{Prepartal Management}

Manipulation of both prepartum cow adiposity and overall energy intake via pasture allocation (i.e., cow/ $\mathrm{m}^{2}$ ) had a large effect on activity and expression of enzymes involved in the one-carbon metabolism, transsulfuration pathway, and TCA cycle, including their metabolism. Of note is the discrepancy between mRNA abundance and activity of the enzymes related to the target pathways (e.g., BHMT, MTR, CBS). Overall, with the exception of MTR expression, changes due to time were congruent at the mRNA and activity level. Abundance of MTR mRNA remained constant despite the change in activity. However, changes in mRNA abundance due to BCS and feeding level manipulation were not reflected in changes in activity. Previous research studying the effect of rumen-protected methionine or choline supplementation in transition dairy cows also reported these discrepancies (Zhou et al., 2017). Although most often this is the case, the
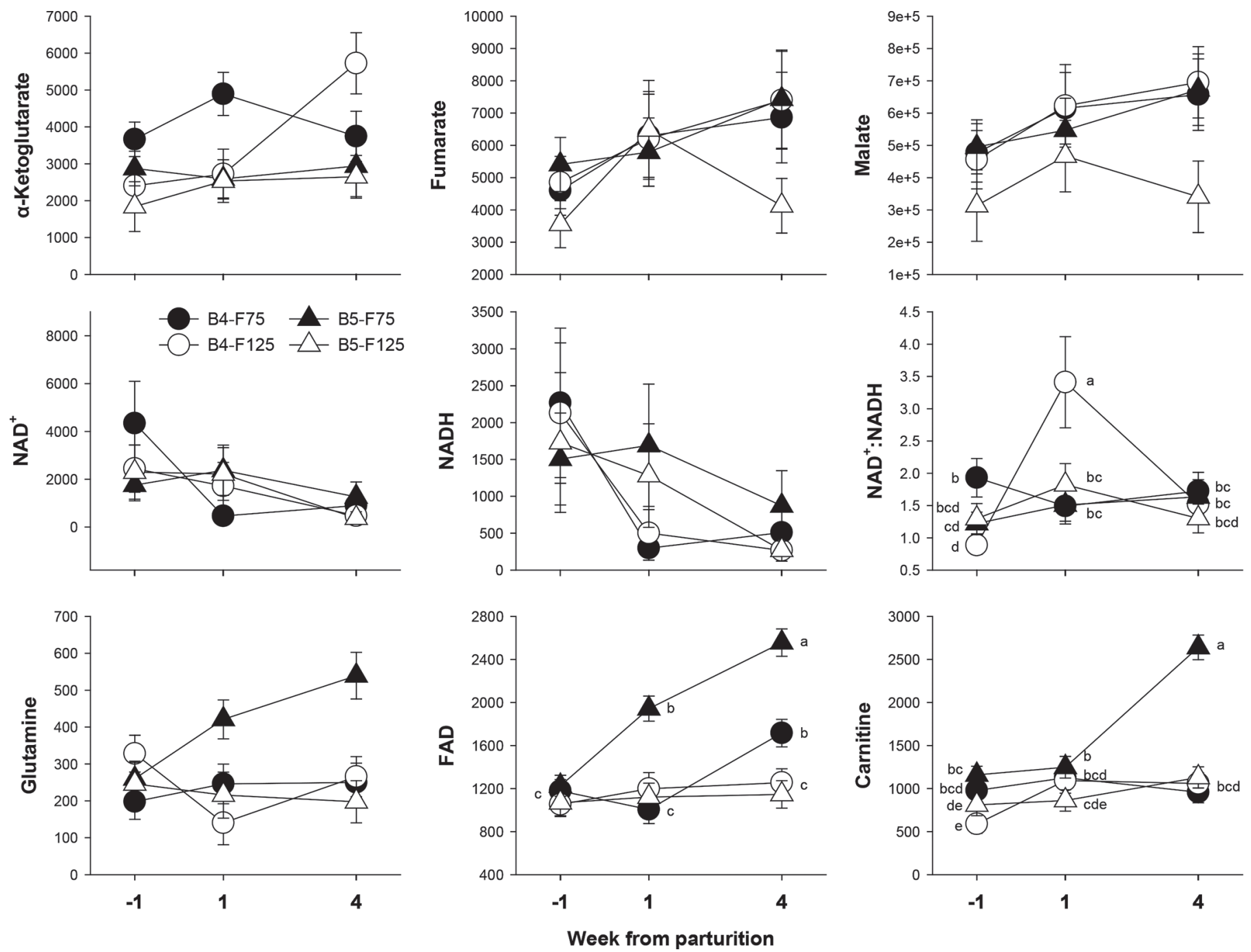

Figure 5. Relative peak area count (PAC/mg of protein) of metabolites associated with hepatic energy metabolism at -1 , 1, and 4 wk around parturition analyzed via a liquid chromatography (LC)/MS/MS approach in liver tissue of cows with different prepartum BCS (B, 4 or 5 on a 10-point scale) and different feed allowance prepartum (F, 75 or $125 \%$ of estimated energy requirements). FAD = flavin adenine dinucleotide. Means with different letters $(\mathrm{a}-\mathrm{e})$ at a given time differ (interaction $P \leq 0.05$ ). Vertical bars denote SEM. 
reader is reminded that mRNA expression and activity of the translated protein are not always in a direct relationship.

Overall, data support the idea of greater flux of nutrients through these pathways in optimally conditioned cows and in cows that were feed restricted prepartum (e.g., increased metabolite relative PAC, and mRNA expression). A few exceptions have to be noted: MTR activity and $\alpha$-ketoglutarate PAC were greater in thin cows, and CBS activity was greater in overfed cows, despite all its downstream metabolites having greater PAC in feed-restricted cows. The latter suggested a negative feedback effect. Because these metabolic pathways are integrated with energy status, and countless studies have demonstrated that BCS, DMI, and energy balance around parturition can be altered by management (reviewed elsewhere, Roche et al., 2009; Drackley and Cardoso, 2014), we speculate that the differences highlight a better energy and overall nutritional status in BCS5 or prepartum feed-restricted cows.

As the major inputs of the one-carbon metabolism (e.g., folate, methionine, choline) are naturally present in significant quantities in green pasture (NRC, 2001), it is logical that a better energy status (e.g., through greater DMI) may have led to greater concentrations of intermediates of this cycle and related pathways.

Concerning the BCS effects detected in the present study, a direct relationship with calving adiposity and postpartum DMI and NEB has been observed in grazing conditions. Thinner cows often have greater DMI and more positive NEB postpartum compared with fat cows (Roche et al., 2009). However, compared with optimally conditioned cows, thin cows have similar energy balance, but slightly lower DMI and greater muscle mass mobilization after calving (Pires et al., 2013). Furthermore, thinner cows are at a greater risk of being afflicted by diseases and often demonstrate signs of poorer welfare compared with optimally conditioned cows (Roche et al., 2009). Thus, we speculate that the greater PAC of metabolites in the one-carbon, transsulfuration, and TCA cycle pathways in BCS5 compared with BCS4 cows indicate a better metabolic and health status.

As DMI is difficult to estimate in grazing systems, energy balance cannot be directly calculated. Plasma fatty acids, BHB, and cholesterol, all greater in BCS5 compared with BCS4 cows, suggest a more pronounced $\mathrm{NEB}$, which triggered a greater degree of mobilization in optimally conditioned score cows. Our previous data combining plasma markers and subcutaneous adipose tissue mRNA expression (Vailati-Riboni et al., 2016a) suggested diminished capacity of the adipose tissue of thin animals to release the already low fat reserves in the postpartum, thus, rendering the interpretation of these data complicated in the context of energy balance. However, combined with greater production, better milk composition, lower inflammatory status, and better reproduction performance compared with thin animals (Roche et al., 2015), we speculate that optimally conditioned score cows underwent transition into lactation at a better energy status than thin, underconditioned cows. Concerning feed management, blood parameters were not greatly affected in the current subset of cows. As similar levels of free fatty acids were observed between feed-restricted and overfed animals, the slightly greater cholesterol concentration in feedrestricted compared with overfed cows might indicate a better ability to handle triacylglycerol repacking into lipoproteins.

Despite a lack of interactions of BCS and prepartal feeding regimen for BHMT and MTR activity, and for mRNA abundance of all detected genes, the metabolites measured highlight a consistently greater flux throughout the one-carbon metabolism, methionine cycle, and their related pathways in feed-restricted, optimally conditioned cows. These results confirm our previous hypothesis and recommendations regarding the use of separate prepartal nutritional strategies based on BCS at dry-off. Not many interactions were detected for thin animals, who compared with optimally conditioned cows, displayed the greatest response at a transcription level (Vailati-Riboni et al., 2016). However, the greater CBS enzyme activity in overfed BCS4 cows, together with methionine, cysteinesulfinate, and hypotaurine PAC comparable with those of feed-restricted BCS5 cows, suggested a greater flux through the transsulfuration pathway. As such, optimally conditioned feedrestricted cows and thin-overfed cows should be better geared to withstand the oxidative stress and inflammatory environment that characterizes the postpartum period.

The postpartum increase in haptoglobin, IL-1 $\beta$, IL-6, and ROS across all groups indicate that cows experienced a certain degree of both oxidative stress and inflammation (Moyes et al., 2010; Loor et al., 2013a,b). Compared with thinner cows, both greater TAC and lower ROS in the circulation again suggest that optimally conditioned score cows (BCS5) underwent a better transition into lactation. Despite the lack of change in oxidant levels between overfed and feed-restricted cows, it seems plausible that overfeeding would have provided cows with greater amounts of antioxidants (e.g., vitamin $\mathrm{A}$ and $\mathrm{E}$ ), probably from the greater intake of pasture. Despite the fact that at the hepatic level the generation of taurine and glutathione appeared greater in feed-restricted counterparts (B5F75), overfed optimally conditioned score cows (B5F125) displayed the peak of TAC right after parturition. Further 
studies are needed to understand the fate of hepatic antioxidants in the circulation and other metabolically active tissues, and the contribution of diet to the cow's antioxidant pool.

\section{Transition Period}

The work of Zhou et al. (2017) highlighted the importance of one-carbon metabolism in transition dairy cows reared in intense TMR-based confinement systems. They reported a 130 and $26 \%$ increase of the hepatic activity of BHMT and MTR, respectively, around parturition, and a similar response $(+72 \%)$ in BHMT hepatic abundance, but no changes in $M T R$ abundance. Similarly, they reported a 20 and $13 \%$ increase in hepatic CBS activity and abundance, respectively, postpartum, when compared with prepartum.

Despite similarities in the physiological response between grazing cows and their higher producing TMRfed counterparts (Kay et al., 2015), our data appear to underscore differences in one-carbon and transsulfuration pathway activity between the 2 systems. For instance, BHMT activity and mRNA abundance were the only parameters in pasture cows that resembled the trends reported in confinement systems. However, activity values, despite being similar prepartum, were half of those identified previously in TMR-fed cows (Zhou et al., 2017; Vailati-Riboni et al., 2019). The identified increase in BHMT activity was accompanied by an increase in PAC of N,N-DG and choline, the products of the reaction, suggesting an increase in flux through the enzyme. The increase in PAC of choline and butyrobetaine/acetylcholine, which feed betaine to BHMT, suggests they might have driven the increase in enzymatic activity. Despite the increase in PAC of metabolites supplying substrates to MTR (e.g., folate, glycine, serine), its activity decreased postpartum; this is contrary to what was reported in TMR-fed cows (Zhou et al., 2017; Vailati-Riboni et al., 2019). Furthermore, the 2- to 3-fold greater activity prepartum and early postpartum in pasture-fed cows suggested a more important role of this enzyme in grazing animals probably due to the high concentration of folate in their diet, a precursor of 5-methyl-tetrahydrofolate and substrate of MTR, which is abundant in green leafy forage (Dong and Oace, 1975).

Concerning the transsulfuration pathway, the fact that homocysteine was undetectable, and that we detected a greater PAC of its metabolites (e.g., cystathionine, hypotaurine, serine) led us to speculate an increased flux postpartum. However, contrary to what was reported in TMR-based systems (Zhou et al., 2017), the activity and abundance of $C B S$ decreased postpartum.
Furthermore, in grazing cows activity values were close to half of those in higher-producing TMR-fed cows.

All these substantial differences in BHMT, MTR, and CBS activity trends throughout the transition period led us to speculate a different load on the metabolic activity of the one-carbon metabolism and transsulfuration pathways. The unique trends during the transition period between production systems might be explained by the difference in demand for lactation (e.g., lower milk production) and in nutrient intake.

\section{CONCLUSIONS}

Overall, the combination of data at multiple levels (mRNA, enzyme activity, metabolomics, blood biomarkers) underscores the strong influence of both prepartum BCS and feeding management on the onecarbon metabolism and transsulfuration pathway. This response might be connected to changes in energy and oxidant status. A strong interaction between the 2 factors was particularly evident at the metabolomics level, but further studies are needed to assess the effect of these changes on the cow's physiological status. The activity patterns over time of hepatic enzymes controlling these pathways highlight differences in the metabolic progression of seasonal grazing cowss compared with their counterparts reared in TMR-based, higher yield, confinement systems.

\section{ACKNOWLEDGMENTS}

The authors thank Jason Philips (farm manager, Scott Farm, DairyNZ, Hamilton, New Zealand) and his capable team, as well as Stu Morgan, Kate Watkins, Hamish Hodgson, and Chris Roach for technical support, and Barbara Dow and Barbara Kuhn-Sherlock for statistical analysis and advice (DairyNZ). This research was supported by New Zealand dairy farmers through DairyNZ Inc. (RD1403) and the Ministry of Business, Innovation, and Employment (DRCX1201; Wellington, New Zealand). The authors have not stated any conflicts of interest.

\section{REFERENCES}

Abuelo, A., J. Hernandez, J. L. Benedito, and C. Castillo. 2015. The importance of the oxidative status of dairy cattle in the periparturient period: Revisiting antioxidant supplementation. J. Anim. Physiol. Anim. Nutr. (Berl.) 99:1003-1016. https://doi.org/10 $.1111 /$ jpn.12273.

Boutflour, R. B. 1928. Limiting factors in the feeding and management of milk cows. Pages 15-20 in Report of Proceedings of 8th World's Dairy Congress, London, UK.

Coleman, D. N., A. Alharthi, V. Lopreiato, E. Trevisi, M. Miura, Y.X. Pan, and J. J. Loor. 2019. Choline supply during negative nutrient balance alters hepatic cystathionine $\beta$-synthase, intermediates 
of the methionine cycle and transsulfuration pathway, and liver function in Holstein cows. J. Dairy Sci. 102:8319-8331. https://doi .org/10.3168/jds.2019-16406.

Dong, F. M., and S. M. Oace. 1975. Folate concentration and pattern in bovine milk. J. Agric. Food Chem. 23:534-538. https://doi.org/ 10.1021/jf60199a014.

Drackley, J. K., and F. C. Cardoso. 2014. Prepartum and postpartum nutritional management to optimize fertility in high-yielding dairy cows in confined TMR systems. Animal 8(Suppl. 1):5-14.

Ducker, G. S., and J. D. Rabinowitz. 2017. One-carbon metabolism in health and disease. Cell Metab. 25:27-42. https://doi.org/10 .1016/j.cmet.2016.08.009.

Graugnard, D. E., M. Bionaz, E. Trevisi, K. M. Moyes, J. L. SalakJohnson, R. L. Wallace, J. K. Drackley, G. Bertoni, and J. J. Loor. 2012. Blood immunometabolic indices and polymorphonuclear neutrophil function in peripartum dairy cows are altered by level of dietary energy prepartum. J. Dairy Sci. 95:1749-1758. https:// doi.org/10.3168/jds.2011-4579.

Graugnard, D. E., K. M. Moyes, E. Trevisi, M. J. Khan, D. Keisler, J. K. Drackley, G. Bertoni, and J. J. Loor. 2013. Liver lipid content and inflammometabolic indices in peripartal dairy cows are altered in response to prepartal energy intake and postpartal intramammary inflammatory challenge. J. Dairy Sci. 96:918-935. https:// doi.org/10.3168/jds.2012-5676.

Grummer, R. R. 2008. Nutritional and management strategies for the prevention of fatty liver in dairy cattle. Vet. J. 176:10-20. https:/ /doi.org/10.1016/j.tvjl.2007.12.033.

Grummer, R. R., M. C. Wiltbank, P. M. Fricke, R. D. Watters, and N. Silva-Del-Rio. 2010. Management of dry and transition cows to improve energy balance and reproduction. J. Reprod. Dev. 56(Suppl.):S22-S28. https://doi.org/10.1262/jrd.1056S22.

Kay, J. K., J. J. Loor, A. Heiser, J. McGowan, and J. R. Roche. 2015. Managing the grazing dairy cow through the transition period: A review. Anim. Prod. Sci. 55:936-942. https://doi.org/10.1071/ AN14870.

Kolver, E. S. 2003. Nutritional limitations to increased production on pasture-based systems. Proc. Nutr. Soc. 62:291-300. https://doi .org/10.1079/PNS2002200.

Loor, J. J., G. Bertoni, A. Hosseini, J. R. Roche, and E. Trevisi. 2013a. Functional welfare - Using biochemical and molecular technologies to understand better the welfare state of peripartal dairy cattle. Anim. Prod. Sci. 53:931-953.

Loor, J. J., M. Bionaz, and J. K. Drackley. 2013b. Systems physiology in dairy cattle: Nutritional genomics and beyond. Annu. Rev. Anim. Biosci. 1:365-392. https://doi.org/10.1146/annurev-animal -031412-103728.

Loor, J. J., H. M. Dann, N. A. Guretzky, R. E. Everts, R. Oliveira, C. A. Green, N. B. Litherland, S. L. Rodriguez-Zas, H. A. Lewin, and J. K. Drackley. 2006. Plane of nutrition prepartum alters hepatic gene expression and function in dairy cows as assessed by longitudinal transcript and metabolic profiling. Physiol. Genomics 27:29-41. https://doi.org/10.1152/physiolgenomics.00036.2006.

Moyes, K. M., J. K. Drackley, D. E. Morin, and J. J. Loor. 2010. Greater expression of TLR2, TLR4, and IL6 due to negative energy balance is associated with lower expression of HLA-DRA and HLA-A in bovine blood neutrophils after intramammary mastitis challenge with Streptococcus uberis. Funct. Integr. Genomics 10:53-61. https://doi.org/10.1007/s10142-009-0154-7.

NRC. 2001. Nutrient Requirements of Dairy Cattle. 7th rev. ed. National Academies Press, Washington, DC.

Pires, J. A. A., C. Delavaud, Y. Faulconnier, D. Pomies, and Y. Chilliard. 2013. Effects of body condition score at calving on indicators of fat and protein mobilization of periparturient Holstein-Friesian cows. J. Dairy Sci. 96:6423-6439. https://doi.org/10.3168/jds.2013 $-6801$.

Roche, J. R., D. P. Berry, J. M. Lee, K. A. Macdonald, and R. C. Boston. 2007. Describing the body condition score change between successive calvings: A novel strategy generalizable to diverse co- horts. J. Dairy Sci. 90:4378-4396. https://doi.org/10.3168/jds .2006-729.

Roche, J. R., P. G. Dillon, C. R. Stockdale, L. H. Baumgard, and M. J. VanBaale. 2004. Relationships among international body condition scoring systems. J. Dairy Sci. 87:3076-3079. https://doi.org/ 10.3168/jds.S0022-0302(04)73441-4.

Roche, J. R., N. C. Friggens, J. K. Kay, M. W. Fisher, K. J. Stafford, and D. P. Berry. 2009. Invited review: Body condition score and its association with dairy cow productivity, health, and welfare. J. Dairy Sci. 92:5769-5801. https://doi.org/10.3168/jds.2009-2431.

Roche, J. R., S. Meier, A. Heiser, M. D. Mitchell, C. G. Walker, M. A. Crookenden, M. V. Riboni, J. J. Loor, and J. K. Kay. 2015. Effects of precalving body condition score and prepartum feeding level on production, reproduction, and health parameters in pasture-based transition dairy cows. J. Dairy Sci. 98:7164-7182. https://doi.org/ 10.3168/jds.2014-9269.

Vailati-Riboni, M., F. Batistel, R. R. C. S. Yambao, C. Parys, Y.-X. Pan, and J. J. Loor. 2019. Hepatic cystathionine $\beta$-synthase activity is increased by greater post-ruminal supply of methionine during the periparturient period in dairy cows. Curr. Dev. Nutr. https: //doi.org/10.1093/cdn/nzz128.

Vailati-Riboni, M., M. Kanwal, O. Bulgari, S. Meier, N. V. Priest, C. R. Burke, J. K. Kay, S. McDougall, M. D. Mitchell, C. G. Walker, M. Crookenden, A. Heiser, J. R. Roche, and J. J. Loor. 2016a. Body condition score and plane of nutrition prepartum affect adipose tissue transcriptome regulators of metabolism and inflammation in grazing dairy cows during the transition period. J. Dairy Sci. 99:758-770. https://doi.org/10.3168/jds.2015-10046.

Vailati-Riboni, M., S. Meier, C. R. Burke, J. K. Kay, M. D. Mitchell, C. G. Walker, M. A. Crookenden, A. Heiser, S. L. Rodriguez-Zas, J. R. Roche, and J. J. Loor. 2016b. Prepartum body condition score and plane of nutrition affect the hepatic transcriptome during the transition period in grazing dairy cows. BMC Genomics 17:854. https://doi.org/10.1186/s12864-016-3191-3.

Vailati Riboni, M., S. Meier, N. V. Priest, C. R. Burke, J. K. Kay, S. McDougall, M. D. Mitchell, C. G. Walker, M. Crookenden, A. Heiser, J. R. Roche, and J. J. Loor. 2015. Adipose and liver gene expression profiles in response to treatment with a nonsteroidal antiinflammatory drug after calving in grazing dairy cows. J. Dairy Sci. 98:3079-3085. https://doi.org/10.3168/jds.2014-8579.

Wu, H., A. D. Southam, A. Hines, and M. R. Viant. 2008. Highthroughput tissue extraction protocol for NMR- and MS-based metabolomics. Anal. Biochem. 372:204-212. https://doi.org/10 .1016/j.ab.2007.10.002.

Zhou, Z., T. A. Garrow, X. Dong, D. N. Luchini, and J. J. Loor. 2017. Hepatic activity and transcription of betaine-homocysteine methyltransferase, methionine synthase, and cystathionine synthase in periparturient dairy cows are altered to different extents by supply of methionine and choline. J. Nutr. 147:11-19. https://doi.org/10 $.3945 /$ jn.116.240234.

Zhou, Y. F., Z. Zhou, F. Batistel, I. Martinez-Cortés, R. T. Pate, D L. Luchini, and J. J. Loor. 2018. Methionine and choline supply alter transmethylation, transsulfuration, and cytidine 5'-diphosphocholine pathways to different extents in isolated primary liver cells from dairy cows. J. Dairy Sci. 101:11384-11395. https://doi .org/10.3168/jds.2017-14236.

\section{ORCIDS}

M. Vailati-Riboni ํㅜ https://orcid.org/0000-0002-8854-8702

M. Crookenden (๑) https://orcid.org/0000-0002-6137-2006

J. K. Kay ๑ https://orcid.org/0000-0002-4024-3168

S. Meier (1) https://orcid.org/0000-0002-4386-7734

A. Heiser ๑ https://orcid.org/0000-0003-0389-6132

J. R. Roche (1) https://orcid.org/0000-0002-4165-9253

J. J. Loor ๑ https://orcid.org/0000-0003-1586-4365 